\title{
The role of childhood emotional maltreatment and body image dissatisfaction in problematic smartphone use among adolescents
}

\author{
Emrah Emirtekin $^{\mathrm{a}}$, Sabah Balta ${ }^{\mathrm{b}}$, İrfan Sural ${ }^{\mathrm{c}}$, Kagan Kircaburun $^{\mathrm{d}, *}$, Mark D. Griffiths ${ }^{\mathrm{e}}$, \\ Joel Billieux ${ }^{\mathrm{f}}$ \\ a The Centre for Open and Distance Learning, Yaşar University, Izmir, Turkey \\ ${ }^{\mathrm{b}}$ School of Applied Sciences, Yaşar University, İzmir, Turkey \\ ${ }^{\mathrm{c}}$ Computer and Instructional Technologies Department, Osmangazi University, Eskişehir, Turkey \\ ${ }^{\mathrm{d}}$ Computer and Instructional Technologies Department, Duzce University, Duzce, Turkey \\ ${ }^{\mathrm{e}}$ International Gaming Research Unit, Psychology Department, Nottingham Trent University, United Kingdom \\ ${ }^{\mathrm{f}}$ Addictive and Compulsive Behaviours Lab, Institute for Health and Behaviour, University of Luxembourg, Esch-sur-Alzette, Luxembourg
}

\section{A R T I C L E I N F O}

\section{Keywords:}

Problematic smartphone use

Childhood emotional maltreatment

Maltreatment

Body image

Depression

Social anxiety

\begin{abstract}
A B S T R A C T
Growing empirical evidence has identified specific psychological and contextual risk factors associated with problematic smartphone use (PSU). However, the potential direct and indirect impact of childhood emotional maltreatment (CEM) on PSU remains largely unexplored, despite the established role of CEM in the onset of other excessive, problematic, and addictive behaviors. Consequently, the purpose of the present study was to test the direct and indirect relationships of emotional abuse and neglect (two facets of CEM) with PSU via specific mediational pathways including body image dissatisfaction (BID), social anxiety, and depression. The sample comprised 443 adolescents who completed a questionnaire that included assessment tools of aforementioned variables. Multiple mediation model results indicated that CEM was directly and indirectly associated with PSU via BID, depression, BID-related depression, and BID-related social anxiety. Results suggested that emotionally traumatic experiences were associated with PSU in adolescents and that this relationship may partially be explained by BID and psychosocial risk factors. The present study draws caution to the amplifying roles of CEM and BID on increased PSU. The results of the study have important clinical and public health implications, but additional research is needed before interventions can be developed and implemented on the basis of present results.
\end{abstract}

\section{Introduction}

Smartphones have become an important part of everyday life and communication between individuals. Over the past decade, the ratio of smartphone users has increased from $10 \%$ in 2011 to $36 \%$ in 2018 worldwide (Statista, 2018). These statistics are even higher among adolescents with $95 \%$ of them owning or having access to smartphones in many countries (Anderson and Jiang, 2018). In contemporary societies, the latest generation of smartphones can be used for a variety of different leisure and non-leisure activities (e.g., social media use, streaming, gaming, gambling, shopping, work- and study-related activities, instant messaging). It could even be argued that smartphones are rapidly replacing personal computers and becoming individuals' personal assistants (Elgan, 2017).

However, despite its facilitating uses, research has demonstrated that, for a minority of individuals, smartphone use can be problematic and that its use can become uncontrolled, leading to various types of negative consequences at personal, social, and/or educational/occupational levels (Billieux, 2012; Billieux et al., 2015). Various studies conducted internationally have consistently reported that a non-negligible proportion of adolescents and teenagers perceive themselves as problematic smartphone users (Beison and Rademacher, 2016; Haug et al., 2015; Kim et al., 2015; Lopez-Fernandez et al., 2017; Smetaniuk, 2014). Moreover, some adolescents and young adults display what some have termed 'addictive' use of smartphones, such as loss of control, progressive and problematic increase in smartphone use, and withdrawal-like symptoms (Chen et al., 2016; Griffiths, 2005; Körmendi et al., 2016; Smetaniuk, 2014).

Problematic smartphone use (PSU), which has been reported as being more prevalent among adolescents compared to adults

\footnotetext{
* Corresponding author.

E-mail address: kircaburunkagan@gmail.com (K. Kircaburun).
} 
(Haug et al., 2015), has repeatedly been associated with negative outcomes including self-reported measures of depression and anxiety symptoms in a community sample, perceived stress among a representative sample of undergraduates, impairments in general health and wellness, academic anxiety and procrastination among students, as well as with lower levels of sleep quality, life satisfaction, and physical activity (Demirci et al., 2015; Haug et al., 2015; Kim et al., 2015; Long et al., 2016; Xie et al., 2018; Yang et al., 2018). PSU has also been associated with greater risk for different types of physical injuries, including car-related accidents (Kim et al., 2017).

According to the Interaction of Person-Affect-Cognition-Execution (I-PACE) model (Brand et al., 2016), a wide range of inter-related risk factors, mediators, and moderators account for problematic online behaviors, including core personal characteristics such as biopsychological constitution (e.g., early childhood experiences, temperamental dispositions) and psychopathological vulnerabilities (e.g., body image dissatisfaction, depression, anxiety). In the I-PACE model, these core components are postulated to interact and facilitate different types of online problematic behaviors (Brand et al., 2016).

Despite the large extant literature regarding the psychosocial and psychopathological risk factors for PSU (see Billieux, 2012 and Billieux et al., 2015, for reviews), the effects of childhood emotional maltreatment (corresponding to the 'early childhood experiences' component of the I-PACE model) remains unclear. Childhood emotional maltreatment (CEM), which is the most prevalent form of child maltreatment among adolescents (Schimmenti et al., 2017), has been defined as children receiving insufficient support for emotional and psychological needs (e.g., love, belonging) from parents and/or being exposed to verbal assaults that generate impairments in a child's sense of worth and wellbeing (Bernstein et al., 2003). Indeed, because emotionally maltreated children feel unloved, flawed, and worthless, they are more likely to experience emotional, social, and behavioral developmental problems while growing up (Maguire et al., 2015).

A frequent consequence of CEM is a vulnerability to developing various addictive behaviors (Brand et al., 2016). For example, a study conducted by Caretti et al. (2018) showed that the fact of having experienced traumatic experiences was more strongly correlated with problematic internet use symptoms than with other types of excessive or addictive behaviors (e.g., drug and alcohol abuse, problematic gambling). Another recent and preliminary study found that childhood maltreatment was positively associated with problematic social media use and that this relationship was partially explained by depressive symptoms (Worsley et al., 2018). Moreover, among different forms of child maltreatment, only emotional neglect/abuse has been significantly positively correlated with problematic internet use among adolescents (Schimmenti et al., 2017), and in another study, emotional abuse was the most important predictor of problematic internet use among university students (Dalbudak et al., 2014). Consequently, given that both internet and smartphones can be considered as 'mediums' that can fuel problematic online behaviors (Baggio et al., 2018; Griffiths, 2000; Starcevic and Aboujaoude, 2017), CEM should lead to higher PSU as well.

CEM is known for playing a pivotal role in the development of body image dissatisfaction (BID; Meston et al., 1999). For example, it has been shown that individuals with body dysmorphic disorder have a prevalent history (around 60\%) of emotional abuse and neglect (Didie et al., 2006). For instance, perceived traumatic conditions have been positively and moderately correlated to body dissatisfaction symptoms among a large clinical sample of patients with eating disorders (Franzoni et al., 2013). It may be that adolescents who have been exposed to traumatizing emotional maltreatment such as demeaning behaviors, criticizing remarks, and insults tend to develop pathological self-criticism and impaired self-perception (Dunkley et al., 2010; Glassman et al., 2007), making them more vulnerable to a wide range of psychopathological symptoms (Kostanski and Gulloni, 1998; Pinto and Phillips, 2005). BID has also been associated with problematic internet use (Koronczai et al., 2013; Lemenager et al., 2018), potentially suggesting that individuals with low body image satisfaction overuse the internet to relieve the related negative affect (Brand et al., 2016). For the reasons explained above (that both internet and smartphones are mediums for potential excessive online activities; for example, see Baggio et al., 2018), it can similarly be expected that individuals with BID are at risk for PSU.

Moreover, emotionally maltreated children are more prone to present with depression (Gibb et al., 2004) and social anxiety (Calvete, 2014). A meta-analytic review concluded that psychological (e.g., emotional) abuse and neglect is strongly associated with depression (Infurna et al., 2016). Another study conducted with adolescents and young adults reported a positive relationship between CEM and anxiety disorders (Schimmenti and Bifulco, 2015). Moreover, among various types of maltreatment, emotional neglect/abuse has an important enhancing role in the development of internalizing and externalizing psychopathology (Infurna et al., 2016).

It is well established that depression and social anxiety are risk factors for higher PSU, which has led some scholars to conceptualize PSU as a maladaptive coping strategy to deal with distress and psychopathological symptoms (Elhai et al., 2018a, b; Enez Darcin et al., 2016). Typically, individuals with low distress tolerance and high boredom proneness are more likely to display PSU as a way to deal with their emotional problems (Elhai et al., 2018b, 2017). It has also been suggested that smartphone use can constitute an avoidance strategy for individuals characterized by social anxiety (Enez Darcin et al., 2016). However, it is worth mentioning that the aforementioned constructs may have bidirectional relationships. For instance, excessive smartphone use may lead to higher psychopathological symptoms and negative consequences (e.g., depression, dissatisfaction with life, diminished academic performance, see Samaha and Hawi, 2016; Selvaganapathy et al., 2017; Tan et al., 2016). Nevertheless, our theoretical rationale in the present study is the I-PACE model (Brand et al., 2016) and we therefore considered the aforementioned psychological components as possible risk factors for PSU.

Consequently, the present study investigated the role of CEM and BID on PSU via the testing of a multiple mediation model while simultaneously controlling for gender and age because females and younger students are more prone to present PSU (Billieux, 2012). Based on the theoretical assumptions of the I-PACE model and the extant empirical literature, it was hypothesized that adolescents who suffered from emotional maltreatment as a child would be more prone to engage in PSU. It was also postulated that BID would be directly associated with PSU and would mediate the relationship between CEM and PSU. Furthermore, it was hypothesized that depression and social anxiety would mediate the expected associations between CEM and BID and PSU. The hypothesized associations are depicted in Fig. 1.

\section{Method}

\subsection{Participants and procedure}

The sample comprised 443 adolescents attending a high school in Turkey (60\% female), aged between 14 and 18 years (mean $=15.95$ years, $S D=1.07)$. They completed a series of paper-and-pencil questionnaires. Students were informed about the details of the study in each class and gave their informed consent prior to participation. All students participated in the study anonymously and voluntarily. Ethical approval for the study was received from the provincial directorate of national education committee before the recruitment of the participants, and complied with the Helsinki declaration. Other data collected in the same sample but unrelated to the present study will be presented elsewhere. 


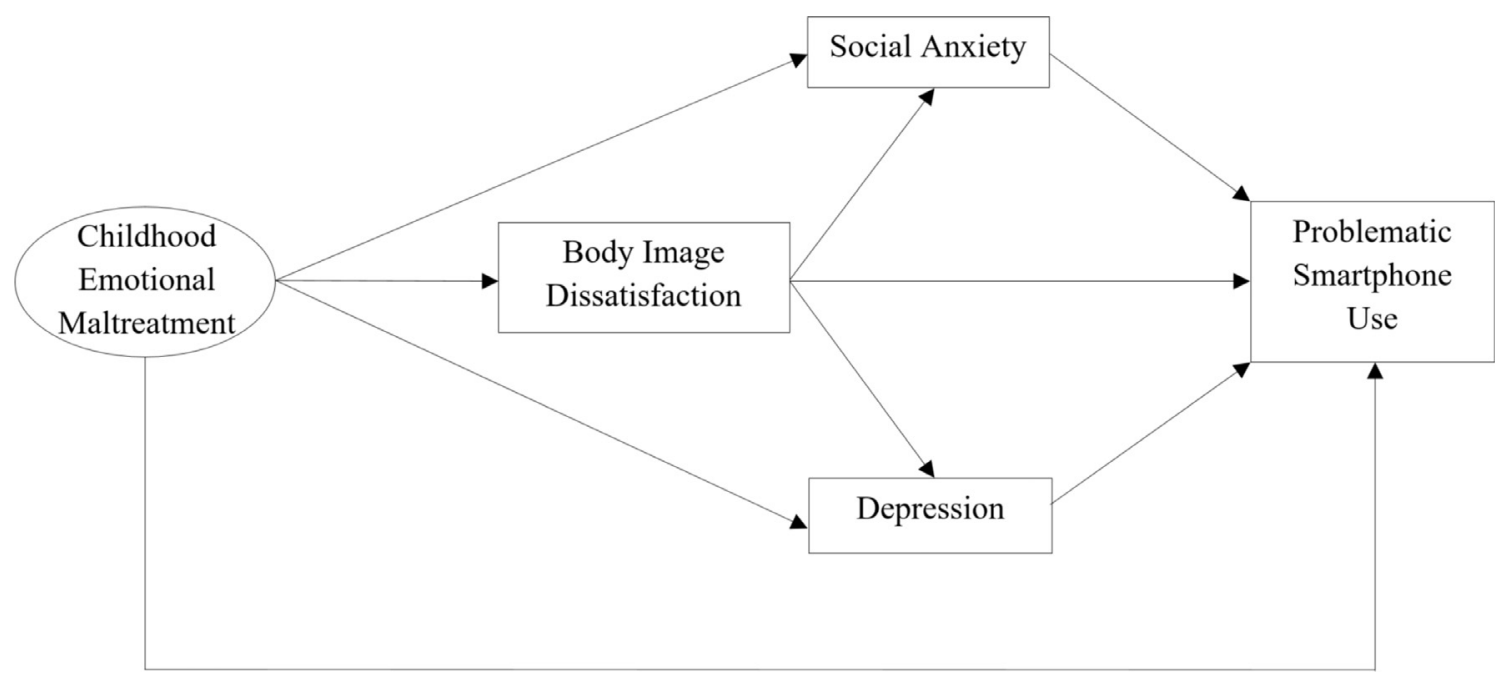

Fig. 1. Hypothesized model.

\subsection{Measures}

\subsubsection{Smartphone Addiction Scale Short Version (Kwon et al., 2013)}

This unidimensional scale comprises ten items assessing addictive use of smartphones (e.g., "I miss planned work due to smartphone use", "I use my smartphone longer than I had intended"). Each item is scored on a 6-point Likert scale from "Strongly disagree" to "Strongly agree". Scores range from 10 to 60 . The Turkish form of the scale has high validity and internal consistency (Demirci et al., 2014) and the Cronbach's $\alpha$ was high in the present study (0.86).

\subsubsection{Childhood Trauma Questionnaire (Bernstein et al., 1994)}

This scale comprises 28 items assessing traumatic experiences (maltreatment) experienced in childhood. Each item is scored on a 5point Likert scale from "never true" to "very often true". Although the original scale comprises five dimensions, only two dimensions (10 items) were used in the present study, namely emotional neglect (e.g., "Felt loved") and emotional abuse (e.g., "Called names by family"). Scores range from 10 to 50 . The Turkish form of the scale has high validity and internal consistency (Sar et al., 2012), and the Cronbach's as of emotional neglect and abuse dimensions were high in the present study (0.81 and 0.89).

\subsubsection{Body Image Dissatisfaction Scale (Harter, 2012)}

This scale comprises five items assessing dissatisfaction with body image (e.g., "I am not pleased with my physical appearance"). Items are scored on a 4-point Likert scale from "strongly disagree" to "strongly agree". Scores range from 4 to 20 . The Turkish form of the scale has high validity and internal consistency (Kircaburun et al., 2018) and the Cronbach's $\alpha$ was high in the present study (0.84).

\subsubsection{Social Anxiety Scale for Adolescents Short Form (Nelemans et al, 2017)}

This scale comprises 12 items assessing three facets of social anxiety, namely fear of negative evaluation (e.g., "I worry about what others think of $m e$ "), social avoidance and distress-new (e.g., "I get nervous when I meet new people"), and social avoidance and distress-general (e.g., "I'm afraid to invite others to do things with me because they might say no"). Each item is scored on a 5-point Likert scale from "never" to "always". Scores range from 12 to 60 . The Turkish form of the scale has high validity and internal consistency (Aydın and Sütçü, 2007). Secondorder confirmatory factor analysis with the Turkish form indicated that the scale can be used unidimensionally $\left(\chi^{2} / \mathrm{df}=2.94\right.$, RMSEA $=0.07$ [CI 90\% $(0.05,0.08)]$, SRMR $=0.05, \mathrm{CFI}=0.97, \mathrm{GFI}=0.95)$, which was done in the present study for parsimony reasons. The Cronbach' $\alpha$ was very high in the present study (0.90).

\subsubsection{Short Depression-Happiness Scale (Joseph et al., 2004)}

The original version of the scale comprised six items, with elevated scores indicating a proneness toward depression whereas lower scores indicating a proneness toward happiness. However, its Turkish adaptation (Kircaburun et al., 2018) comprised two separated dimensions, with three items assessing depressive symptoms ("I felt that life was meaningless", "I felt dissatisfied with my life", "I felt cheerless") and three items assessing happiness (e.g., "I felt that life was enjoyable"). Items are scored on a 4-point Likert scale ranging from "never" to "often". Scores range from 3 to 12 . The Turkish version of the scale composed of two separate factors adequate structural validity $\left(\chi^{2} / \mathrm{df}=1.65\right.$, RMSEA $=0.04$ [CI 90\% $(0.00,0.08)], \quad$ SRMR $=0.05$, CFI $=0.99$, $\mathrm{GFI}=0.99$ ) and internal consistency (Kircaburun et al., 2018). The present study only used the depression subscale and the Cronbach's $\alpha$ was high (0.85).

\subsection{Data analysis}

First, mean scores and standard deviations were computed for all study variables, and Pearson's correlation was utilized to consider the correlations among variables. Second, path analysis was applied to test the hypothesized model (see Fig. 1). Model fit was determined by using widely referred thresholds for goodness of fit indices (Hu and Bentler, 1999). Accordingly, the computed model can be considered as having a good fit if the comparative fit index (CFI) and goodness of fit index (GFI) are above 0.90, and the root mean square error of approximation (RMSEA) and the standardized root mean square residual (SRMR) are below 0.80. In order to compute mediation effects between relevant variables, the bootstrapping method was applied with 5000 bootstrapping samples and $95 \%$ bias-corrected confidence intervals. Finally, significance levels of specific indirect pathways were calculated via using two different estimands, namely ABindirectEffects.AmosEstimandVB and ABCindirectEffect.AmosEstimandVB (Gaskin, 2016). All analyses were carried out with SPSS 23.0 and AMOS 23.0.

\section{Results}

Descriptive statistics and correlation coefficients are reported in Table 1. All study variables were positively correlated with each other and correlation coefficients ranged from small to medium. In the next step, $t$-tests were carried out to determine gender differences across the different variables (Table 2). Results indicated that female adolescents 
Table 1

Descriptive statistics and Pearson's correlations of the study variables.

\begin{tabular}{llllll}
\hline & 1 & 2 & 3 & 4 & 5 \\
\hline 1. Problematic smartphone use & - & & & & \\
2. Childhood emotional maltreatment & $0.23^{* *}$ & - & & & \\
3. Body image dissatisfaction & $0.29^{* *}$ & $0.29^{*}$ & - & & \\
4. Social anxiety & $0.23^{* *}$ & $0.18^{* *}$ & $0.39^{* *}$ & - & \\
5. Depression & $0.26^{* *}$ & $0.33^{* *}$ & $0.39^{* *}$ & $0.24^{* *}$ & - \\
$M$ & 26.26 & 14.72 & 11.59 & 26.51 & 7.45 \\
SD & 9.73 & 5.98 & 3.53 & 9.82 & 2.86 \\
$\quad$ Minimum score & 10 & 10 & 4 & 12 & 3 \\
$\quad$ Maximum score & 60 & 50 & 20 & 60 & 12 \\
\hline
\end{tabular}

${ }^{*} p<0.01$.

** $p<0.001$.

scored significantly higher on all study variables except for CEM (where there were no gender differences).

Next, in order to examine direct and indirect relationships between study variables, path analysis was applied. CEM was included into the model as independent variable, while BID, social anxiety, and depression were specified as mediating variables, and PSU was the outcome variable (see Fig. 1). Finally, gender and age were adjusted for mediator and outcome variables in the model and being female and younger were positively associated with PSU. Goodness of fit indices indicated that the tested model had a good fit to the data $\left(\chi^{2} / d f=0.67\right.$, RMSEA $=0.00 \quad[$ CI $90 \%(0.00,0.05)], \quad S R M R=0.01, \quad$ CFI $=1.00$, $\mathrm{GFI}=1.00$ ).

Path analyses indicated that CEM was associated with PSU directly $(\beta=0.18, p<0.01 ; 95 \%$ CI $[0.06,0.30])$ and indirectly $(\beta=0.10$, $p<0.001$; $95 \%$ CI $[0.06,0.16])$ via BID, depression, BID-related depression, and BID-related social anxiety. BID was also associated with PSU directly ( $\beta=0.11, p<0.05 ; 95 \%$ CI $[0.01,0.22]$ ) and indirectly ( $\beta=0.08, p<0.01 ; 95 \%$ CI $[0.03,0.13])$ via depression, and social anxiety (Table 3 ). Finally, both depression ( $\beta=0.14, p<0.05$; $95 \%$ CI $[0.02,0.24])$ and social anxiety $(\beta=0.11, p<0.05$; $95 \%$ CI $[0.01$, $0.20]$ ) were direct predictors of PSU. However, it should be noted that effect sizes were small. The final model explained $19 \%$ of the variance in PSU (see Fig. 2).

\section{Discussion}

The present study examined how the direct association between CEM and PSU is mediated by several psychological risk factors, including BID, depression, and social anxiety while controlling for gender and age. The first important result of the present study is that CEM and BID were direct predictors of PSU. Such associations, to the best of authors' knowledge, have never been reported in the literature previously. However, it should be noted that the effect sizes were small. The present findings are also consistent with some predictions of the IPACE model (Brand et al., 2016). More specifically, the study supports the contention that environmental factors such as child maltreatment postulated in the I-PACE to shape biopsychological constitution - are associated with PSU.
Table 3

Standardized estimates of total, direct and indirect effects on problematic smartphone use.

\begin{tabular}{llll}
\hline & Effect & S.E. & $\%$ explained of total effect \\
\hline CEM $\rightarrow$ PSU (total effect) & $0.28^{* * *}$ & 0.06 & - \\
CEM $\rightarrow$ PSU (direct effect) & $0.18^{* *}$ & 0.07 & $64 \%$ \\
CEM $\rightarrow$ PSU (total indirect effect) & $0.10^{* * *}$ & 0.04 & $36 \%$ \\
CEM $\rightarrow$ BID $\rightarrow$ PSU & $0.04^{*}$ & 0.05 & $25 \%$ \\
CEM $\rightarrow$ Depression $\rightarrow$ PSU & $0.04^{*}$ & 0.05 & $25 \%$ \\
CEM $\rightarrow$ BID $\rightarrow$ Depression $\rightarrow$ PSU & $0.01^{*}$ & 0.02 & $6 \%$ \\
CEM $\rightarrow$ BID $\rightarrow$ Social anxiety $\rightarrow$ PSU & $0.01^{*}$ & 0.02 & $6 \%$ \\
& & & \\
BID $\rightarrow$ PSU (total effect) & $0.19^{* * *}$ & 0.05 & - \\
BID $\rightarrow$ PSU (direct effect) & $0.11^{*}$ & 0.05 & $58 \%$ \\
BID $\rightarrow$ PSU (total indirect effect) & $0.08^{* *}$ & 0.03 & $42 \%$ \\
BID $\rightarrow$ Depression $\rightarrow$ PSU & $0.04^{*}$ & 0.05 & $21 \%$ \\
BID $\rightarrow$ Social anxiety $\rightarrow$ PSU & $0.04^{*}$ & 0.06 & $21 \%$ \\
& & &
\end{tabular}

Note: $\mathrm{CEM}=$ Childhood emotional maltreatment; BID = Body image dissatisfaction; PSU = Problematic smartphone use. Only significant indirect effects are shown in the table.

$$
\begin{aligned}
& { }^{*} p<0.05 . \\
& { }^{* *} p<0.01 . \\
& { }^{* * * *} p<0.001 .
\end{aligned}
$$

As expected, CEM was directly associated with PSU. This result is consistent with previous studies that have reported a relationship between childhood maltreatment and problematic social media and general internet use, both of which have significant overlaps with PSU (Dalbudak et al., 2014; Worsley et al., 2018). The results of the present study are consistent with the view that adolescents who have experienced maltreatment are susceptible to avoiding negative feelings and inner conflicts arising from specific painful memories via the distraction provided by smartphone use, or to present with a dissociative mechanism consisting in using the smartphone to prevent their minds from reactivating traumatic states connected to their CEM (Schimmenti and Caretti, 2010). These maladaptive coping mechanisms ultimately are likely to favor the development of excessive and/or addictive smartphone use. Moreover, adolescents can also display PSU as a result from attempts to achieve a higher self-direction and sense of mastery after being exposed to maltreatment that damaged their self-image and selfefficacy (Schimmenti et al., 2017). The results of the present study are therefore in accordance with the hypothesis that maltreated children might engage in PSU to cope with their CEM-related post-traumatic stress (Contractor et al., 2017).

The present study also found that BID was a positive predictor of PSU and partially accounted for the association between CEM and PSU. Adolescents who had a perceived history of CEM experienced higher dissatisfaction with their body image and in turn, were more problematic smartphone users. This is in line with the previous studies showing that BID is positively associated with problematic internet use (Koronczai et al., 2013; Lemenager et al., 2018), given that both internet and smartphones are mediums of problematic technologymediated behaviors (Baggio et al., 2018). BID is established as having serious detrimental effects on individuals' self-esteem (Koronczai et al.,

\begin{tabular}{|c|c|c|c|c|}
\hline & Female $(n=266)$ & Male $(n=177)$ & $t$-test & Cohen's $d$ \\
\hline Problematic smartphone use & $27.81 \pm 9.79$ & $23.93 \pm 9.17$ & $4.24^{* * * *}$ & 0.41 \\
\hline Childhood emotional maltreatment & $14.55 \pm 5.80$ & $14.97 \pm 6.24$ & -0.72 & 0.07 \\
\hline Body image dissatisfaction & $12.02 \pm 3.68$ & $10.95 \pm 3.18$ & $3.17^{* *}$ & 0.31 \\
\hline Social anxiety & $27.62 \pm 10.02$ & $24.85 \pm 9.31$ & $2.99^{* *}$ & 0.29 \\
\hline Depression & $7.71 \pm 2.77$ & $7.05 \pm 2.96$ & $2.36^{*}$ & 0.23 \\
\hline
\end{tabular}

Table 2

Comparison of the scores of study variables ( $t$-test) between females and males.

\footnotetext{
* $p<0.05$.

*** $p<0.01$.

*** $p<0.001$.
} 


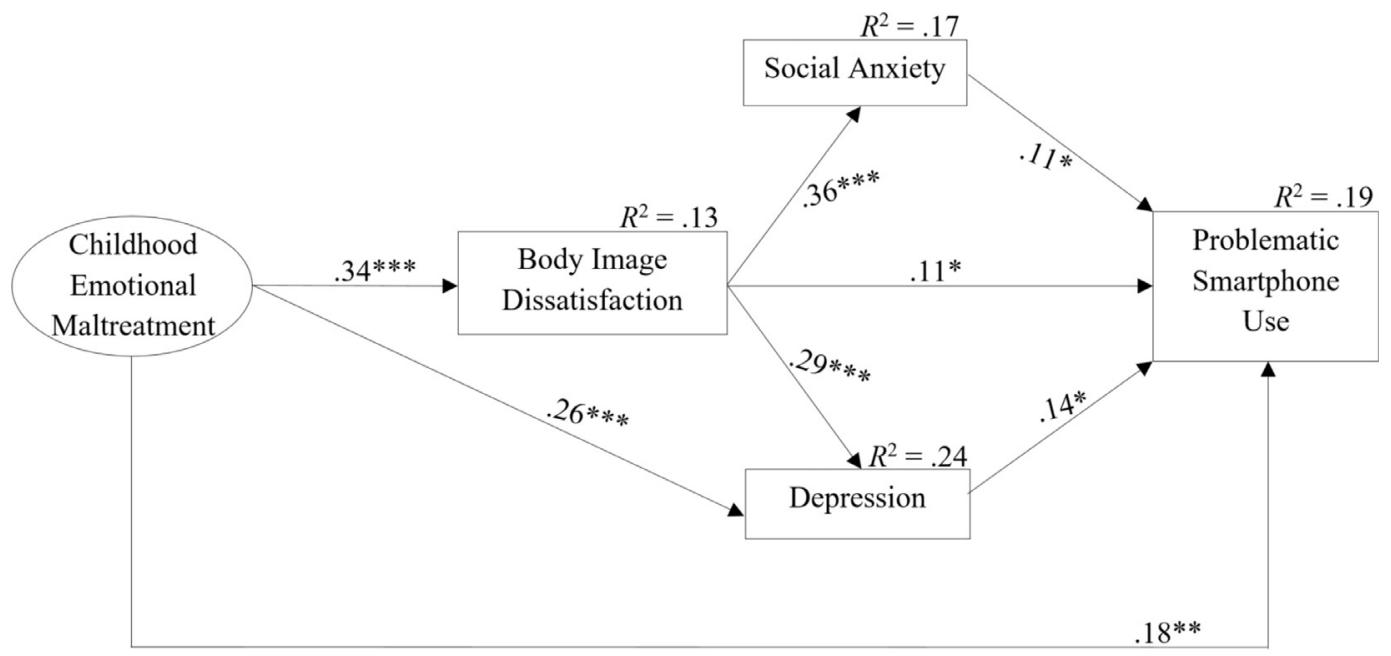

Fig. 2. Final model of the significant path coefficients. For clarity correlations between mediator variables, pathways from control variables to mediator variables, and insignificant pathways were not depicted in the figure. All unidimensional constructs included into the model as observed variables. Childhood emotional maltreatment was included as a latent variable. ${ }^{*} p<.05,{ }^{* *} p<.01,{ }^{* * *} p<.001$.

2013), especially for adolescents, who are going through a crucial and fragile developmental period (Grogan, 2016). Consequently, it is possible, although not directly assessed in the present study, that decreased self-esteem contributes to the positive association observed between BID and PSU (see De-Sola Gutierrez., 2016 for a related discussion and a review).

It was also found that depression and social anxiety were positively associated with PSU. While depression accounted for the relationships of CEM and BID with PSU, social anxiety was a significant mediator between BID and PSU. These findings are aligned with recent literature reviews reporting that depression and social anxiety were the strongest and most consistent psychosocial predictors of technology-mediated disorders (Brand et al., 2016). Several explanations can account for such results. For example, maladaptive emotion regulation strategies engendering depression symptoms (e.g., abstract repeated negative thoughts such as ruminations or worries, see Elhai et al., 2018c) that are relieved through excessive use of mobile technology. It is also reasonable to argue that for socially anxious individuals, smartphonebased online interactions are less stressful than offline social interactions (for example, see the pathway model of problematic smartphone use by Billieux et al. 2015.

When interpreting the results of the present study, a number of limitations should be taken into account. The primary concern is the cross-sectional design. First, the use of this design precludes any conclusions regarding the temporal ordering of, and causal relations among, the constructs. Therefore, while statisticalmediation was tested, mediation in the true mechanistic sense was not examined. Future studies should therefore confirm the results presented here using more representative samples and longitudinal designs. Second, the data were collected using self-report questionnaires, which are known to be affected by response bias (e.g., lack of introspection and social desirability). For instance, given that the items used to assess childhood emotional maltreatment (i.e., CTQ) were not associated with behavioral indicators to guide participants (e.g., items related to physical abuse can be more easily related to tangible outcomes, such as physical injuries), these items leave much room open for idiosyncratic interpretation and subjectivity. As such, the findings cannot exclude the possibility that the emotional abuse and emotional neglect scales may have shown spuriously inflated associations with depression symptoms and other psychological outcomes. Also, given that all constructs were tested simultaneously, and using a similar self-report format, it cannot be ruled out that shared method variance and/or response bias might account for the inter-relationships among the measures. Third, the sample of the study only comprised Turkish adolescent students so the results cannot be generalized to the entire Turkish population (or other populations) and the study should be replicated using representative samples of adults (from both Turkey and other countries). Despite its limitations, the present study is, to the best of authors' knowledge, the first to examine and demonstrate the direct relationships of childhood emotional maltreatment and body image dissatisfaction in relation to PSU. The results of the present study have important clinical and public health implications, but additional research is needed before interventions can be developed and implemented on the basis of the present results.

\section{Supplementary materials}

Supplementary material associated with this article can be found, in the online version, at doi:10.1016/j.psychres.2018.12.059.

\section{References}

Anderson, M., Jiang, J., 2018. Teens, Social Media \& Technology 2018. Retrieved 11 September, 2018, from. http://www.pewinternet.org/2018/05/31/teens-socialmedia-technology-2018/.

Aydın, A., Sütcü, S.T., 2007. Validity and reliability of social anxiety scale for adolescents (SAS-A). Turkish J. Child Adolesc. Mental Health 14, 79-89.

Baggio, S., Starcevic, V., Studer, J., Simon, O., Gainsbury, S.M., Gmel, G., Billieux, J., 2018. Technology-mediated addictive behaviors constitute a spectrum of related yet distinct conditions: a network perspective. Psychol. Addict. Behav. 32, 564-572.

Beison, A., Rademacher, D.J., 2016. Relationship between family history of alcohol addiction, parents' education level, and smartphone problem use scale scores. J. Behav. Addict. 6, 84-91.

Bernstein, D.P., Fink, L., Handelsman, L., Foote, J., Lovejoy, M., Wenzel, K., Ruggiero, J., 1994. Initial reliability and validity of a new retrospective measure of child abuse and neglect. Am. J. Psychiatry 151, 1132-1136.

Bernstein, D.P., Stein, J.A., Newcomb, M.D., Walker, E., Pogge, D., Ahluvalia, T., Zule, W. 2003. Development and validation of a brief screening version of the childhood trauma questionnaire. Child Abuse Negl. 27, 169-190.

Billieux, J., 2012. Problematic use of the mobile phone: a literature review and a pathways model. Curr. Psychiatry Rev. 8, 299-307.

Billieux, J., Maurage, P., Lopez-Fernandez, O., Kuss, D.J., Griffiths, M.D., 2015. Can disordered mobile phone use be considered a behavioral addiction? An update on current evidence and a comprehensive model for future research. Curr. Addict. Rep. 2, 156-162.

Brand, M., Young, K.S., Laier, C., Wölfling, K., Potenza, M.N., 2016. Integrating psychological and neurobiological considerations regarding the development and maintenance of specific Internet-use disorders: an interaction of person-affect-cognition-execution (I-PACE) model. Neurosci. Biobehav. Rev. 71, 252-266.

Calvete, E., 2014. Emotional abuse as a predictor of early maladaptive schemas in adolescents: contributions to the development of depressive and social anxiety symptoms. Child Abuse Negl. 38, 735-746.

Caretti, V., Gori, A., Craparo, G., Giannini, M., Iraci-Sareri, G., Schimmenti, A., 2018. A new measure for assessing substance-related and addictive disorders: the addictive 
behavior questionnaire (ABQ). J. Clin. Med. 7, e194. https://doi.org/10.3390/ jcm7080194.

Chen, J., Liang, Y., Mai, C., Zhong, X., Qu, C., 2016. General deficit in inhibitory control of excessive smartphone users: evidence from an event-related potential study. Front. Psychol. 7, 511.

Contractor, A.A., Weiss, N.H., Tull, M.T., Elhai, J.D., 2017. PTSD's relation with problematic smartphone use: mediating role of impulsivity. Comput. Hum. Behav. 75, $177-183$.

Dalbudak, E., Evren, C., Aldemir, S., Evren, B., 2014. The severity of internet addiction risk and its relationship with the severity of borderline personality features, childhood traumas, dissociative experiences, depression and anxiety symptoms among Turkish university students. Psychiatry Res. 219, 577-582.

De-Sola Gutiérrez, J., Rodríguez de Fonseca, F., Rubio, G., 2016. Cell-phone addiction: a review. Front. Psychiatry 7, 175.

Demirci, K., Akgönül, M., Akpinar, A., 2015. Relationship of smartphone use severity with sleep quality, depression, and anxiety in university students. J. Behav. Addict. 4 85-92.

Demirci, K., Orhan, H., Demirdas, A., Akpinar, A., Sert, H., 2014. Validity and reliability of the Turkish version of the smartphone addiction scale in a younger population. Klin. Psikofarmakol. Bülteni - Bull. Clin. Psychopharmacol. 24, 226-234.

Didie, E.R., Tortolani, C.C., Pope, C.G., Menard, W., Fay, C., Phillips, K.A., 2006 Childhood abuse and neglect in body dysmorphic disorder. Child Abuse Negl. 30, 1105-1115.

Dunkley, D.M., Masheb, R.M., Grilo, C.M., 2010. Childhood maltreatment, depressive symptoms, and body dissatisfaction in patients with binge eating disorder: the mediating role of self-criticism. Int. J. Eat. Disord. 43, 274-281.

Elgan, M., 2017. With smartphones like these, why do we need laptops? Retrieved 11 September, 2018, from. https://www.computerworld.com/article/3241233/ smartphones/with-smartphones-like-these-why-do-we-need-laptops.html.

Elhai, J.D., Vasquez, J.K., Lustgarten, S.D., Levine, J.C., Hall, B.J., 2017. Proneness to boredom mediates relationships between problematic smartphone use with depression and anxiety severity. Soc. Sci. Comput. Rev. https://doi.org/10.1177/ 0894439317741087. Epub ahead of print.

Elhai, J.D., Levine, J.C., Alghraibeh, A.M., Alafnan, A.A., Aldraiweesh, A.A., Hall, B.J. 2018a. Fear of missing out: testing relationships with negative affectivity, online social engagement, and problematic smartphone use. Comput. Hum. Behav. 89, 289-298.

Elhai, J.D., Levine, J.C., O'Brien, K.D., Armour, C., 2018b. Distress tolerance and mindfulness mediate relations between depression and anxiety sensitivity with problematic smartphone use. Comput. Hum. Behav. 84, 477-484.

Elhai, J.D., Tiamiyu, M., Weeks, J., 2018c. Depression and social anxiety in relation to problematic smartphone use: the prominent role of rumination. Internet Res. 28, 315-332.

Enez Darcin, A., Kose, S., Noyan, C.O., Nurmedov, S., Yilmaz, O., Dilbaz, N., 2016. Smartphone addiction and its relationship with social anxiety and loneliness. Behav. Inf. Technol. 35, 520-525.

Franzoni, E., Gualandi, S., Caretti, V., Schimmenti, A., Di Pietro, E., Pellegrini, G., Pellicciari, A., 2013. The relationship between alexithymia, shame, trauma, and body image disorders: investigation over a large clinical sample. Neuropsychiatr. Dis. Treat. 9, 185-193.

Gaskin, J., 2016. Gaskination's Statistics. Retrieved July 22, 2018, from. http://statwiki. kolobkreations.com.

Gibb, B.E., Abramson, L.Y., Alloy, L.B., 2004. Emotional maltreatment from parents, verbal peer victimization, and cognitive vulnerability to depression. Cogn. Ther. Res. $28,1-21$.

Glassman, L.H., Weierich, M.R., Hooley, J.M., Deliberto, T.L., Nock, M.K., 2007. Child maltreatment, non-suicidal self-injury, and the mediating role of self-criticism. Behav. Res. Ther. 45, 2483-2490.

Griffiths, M., 2000. Does internet and computer" addiction" exist? Some case study evidence. CyberPsychol. Behav. 3, 211-218.

Griffiths, M., 2005. A 'components' model of addiction within a biopsychosocial framework. J. Subst. Use 10, 191-197.

Grogan, S., 2016. Body Image: Understanding Body Dissatisfaction in Men, Women and Children. Taylor \& Francis, New York.

Harter, S., 2012. Self-perception Profile For Adolescents: Manual and Questionnaires. University of Denver Press, Denver, CO.

Haug, S., Castro, R.P., Kwon, M., Filler, A., Kowatsch, T., Schaub, M.P., 2015. Smartphone use and smartphone addiction among young people in Switzerland. J. Behav. Addict. 4, 299-307.

Hu, L.T., Bentler, P.M., 1999. Cutoff criteria for fit indexes in covariance structure analysis: conventional criteria versus new alternatives. Struct. Equ. Model. 6, 1-55.

Infurna, M.R., Reichl, C., Parzer, P., Schimmenti, A., Bifulco, A., Kaess, M., 2016. Associations between depression and specific childhood experiences of abuse and neglect: a meta-analysis. J. Affect. Disord. 190, 47-55.

Joseph, S., Linley, P.A., Harwood, J., Lewis, C.A., McCollam, P., 2004. Rapid assessment of well-being: the short depression-happiness scale (SDHS). Psychol. Psychother.: Theory, Res. Pract. 77, 463-478.

Kim, S.E., Kim, J.W., Jee, Y.S., 2015. Relationship between smartphone addiction and physical activity in Chinese international students in Korea. J. Behav. Addict. 4,
200-205.

Kim, H.J., Min, J.Y., Kim, H.J., Min, K.B., 2017. Accident risk associated with smartphone addiction: a study on university students in Korea. J. Behav. Addict. 6, 699-707.

Kircaburun, K., Griffiths, M.D., Billieux, J., 2018. Childhood emotional maltreatment and problematic social media use among adolescents: the mediating role of body image dissatisfaction. Submitted for publication.

Kircaburun, K., Kokkinos, C.M., Demetrovics, Z., Király, O., Griffiths, M.D., Çolak, T.S., 2018. Problematic online behaviors among adolescents and emerging adults: associations between cyberbullying perpetration, problematic social media use and psychosocial factors. Int. J. Mental Health Addict. https://doi.org/10.1007/s11469-018 9894-8. Epub ahead of print.

Koronczai, B., Kökönyei, G., Urbán, R., Kun, B., Pápay, O., Nagygyörgy, K., Demetrovics, Z., 2013. The mediating effect of self-esteem, depression and anxiety between satisfaction with body appearance and problematic internet use. Am. J. Drug Alcohol Abuse 39, 259-265.

Körmendi, A., Brutóczki, Z., Végh, B.P., Székely, R., 2016. Smartphone use can be addictive? A case report. J. Behav. Addict. 5, 548-552.

Kostanski, M., Gullone, E., 1998. Adolescent body image dissatisfaction: Relationships with self-esteem, anxiety, and depression controlling for body mass. J. Child Psychol. Psychiatry $39,255-262$.

Kwon, M., Kim, D.J., Cho, H., Yang, S., 2013. The smartphone addiction scale: development and validation of a short version for adolescents. PLoS One 8, e83558.

Lemenager, T., Hoffmann, S., Dieter, J., Reinhard, I., Mann, K., Kiefer, F., 2018. The links between healthy, problematic, and addicted Internet use regarding comorbidities and self-concept-related characteristics. J. Behav. Addict. 7, 31-43.

Long, J., Liu, T.Q., Liao, Y.H., Qi, C., He, H.Y., Chen, S.B., Billieux, J., 2016. Prevalence and correlates of problematic smartphone use in a large random sample of Chinese undergraduates. BMC Psychiatry 16, 408.

Lopez-Fernandez, O., Kuss, D.J., Romo, L., Morvan, Y., Kern, L., Graziani, P., Schimmenti, A., 2017. Self-reported dependence on mobile phones in young adults: a European cross-cultural empirical survey. J. Behav. Addict. 6, 168-177.

Maguire, S.A., Williams, B., Naughton, A.M., Cowley, L.E., Tempest, V., Mann, M.K., Kemp, A.M., 2015. A systematic review of the emotional, behavioural and cognitive features exhibited by school-aged children experiencing neglect or emotional abuse. Child Care Health Dev. 41, 641-653.

Meston, C.M., Heiman, J.R., Trapnell, P.D., 1999. The relation between early abuse and adult sexuality. J. Sex Res. 36, 385-395.

Nelemans, S.A., Meeus, W.H., Branje, S.J., Van Leeuwen, K., Colpin, H., Verschueren, K., Goossens, L., 2017. Social anxiety scale for adolescents (SAS-A) short form: longitudinal measurement invariance in two community samples of youth. Assessment. https://doi.org/10.1177/1073191116685808. Epub ahead of print.

Pinto, A., Phillips, K.A., 2005. Social anxiety in body dysmorphic disorder. Body Image 2, 401-405.

Samaha, M., Hawi, N.S., 2016. Relationships among smartphone addiction, stress, academic performance, and satisfaction with life. Comput. Hum. Behav. 57, 321-325.

Sar, V., Öztürk, P.E., İkikardeş, E., 2012. Validity and reliability of the Turkish version of childhood trauma questionnaire. Turkiye Klinikleri J. Med. Sci. 32, 1054-1063.

Schimmenti, A., Bifulco, A., 2015. Linking lack of care in childhood to anxiety disorders in emerging adulthood: the role of attachment styles. Child Adolesc. Mental Health 20, 41-48.

Schimmenti, A., Caretti, V., 2010. Psychic retreats or psychic pits? Unbearable states of mind and technological addiction. Psychoanal. Psychol. 27, 115-132.

Schimmenti, A., Passanisi, A., Caretti, V., La Marca, L., Granieri, A., Iacolino, C., Billieux, J., 2017. Traumatic experiences, alexithymia, and Internet addiction symptoms among late adolescents: a moderated mediation analysis. Addict. Behav. 64, 314-320.

Selvaganapathy, K., Rajappan, R., Dee, T.H., 2017. The effect of smartphone addiction on craniovertebral angle and depression status among university students. Int. J. Integr. Med. Sci. 4, 537-542.

Smetaniuk, P., 2014. A preliminary investigation into the prevalence and prediction of problematic cell phone use. J. Behav. Addict. 3, 41-53.

Starcevic, V., Aboujaoude, E., 2017. Internet addiction: reappraisal of an increasingly inadequate concept. CNS Spectr. 22, 7-13.

Statista, 2018. Number of smartphone users worldwide from 2014 to 2020 (in billions). Retrieved 11 September, 2018, from. https://www.statista.com/statistics/330695/ number-of-smartphone-users-worldwide/.

Tan, T., Kuek, A., Goh, S.E., Lee, E.L., Kwok, V., 2016. Internet and smartphone application usage in eating disorders: a descriptive study in Singapore. Asian J. Psychiatry 19, 50-55.

Worsley, J.D., McIntyre, J.C., Bentall, R.P., Corcoran, R., 2018. Childhood maltreatment and problematic social media use: the role of attachment and depression. Psychiatry Res. 267, 88-93.

Xie, X., Dong, Y., Wang, J., 2018. Sleep quality as a mediator of problematic smartphone use and clinical health symptoms. J. Behav. Addict. 7, 466-477.

Yang, Z., Asbury, K., Griffiths, M.D., 2018. An exploration of problematic smartphone use among Chinese university students: Associations with academic anxiety, academic procrastination, self-regulation and subjective wellbeing. Int. J. Mental Health Addict. https://doi.org/10.1007/s11469-018-9961-1. Epub ahead of print. 